\title{
Risk Assessment Regarding the Implementation of Public-Private Partnership Projects in the World Practice
}

\author{
Natalia V. Kuchkovskaya, ${ }^{+*}$ Yuri V. Zabaikin, ${ }^{*}$ Malika U. Baysaeva, ' Irina A. Kosareva, ${ }^{\uparrow}$ and Mauricio
} Calesci ${ }^{i}$

\section{Abstract}

In market conditions, the state bore a heavy burden of functions that might be too heavy and sometimes almost unmanageable because of historical development, deepened by the realities of the world economy, as well as various crisis phenomena repeatedly analysed in this and past centuries. At the same time, combining the possibilities of state regulation and market opportunities of business entities, it is possible to achieve significant results by solving a wide range of issues regarding the provision of public services. The research aims to form the potential structure of the European Union development and global practice in the form of development of publicprivate partnership projects. It is determined by the need that we can agree that the basis of publicprivate partnership (PPP) relations is the interdependence of business and government regulation which is reflected in the existence of the relations between the representatives of public and private sectors. The result of the research demonstrates that the PPP is a form of cooperation in which the state and private sector jointly implement socially significant projects based on the agreement on the distribution of tasks and risks. Indeed, it is an institutional alliance between the state and business established for a certain period for the implementation of a specific project and ceases to exist after its implementation. To accomplish the research objectives, we have developed a methodological approach to the coordination of the economic interests of the PPP participants. The approach includes the implementation of multivariate calculations of the PPP project internal cost using the method of discounted cash flows, revision of the agreement terms and the choice of such values of the PPP agreement parameters.

Keywords: Public-Private Partnership; Project Implementation; Animation Effect; Stagnation Overcoming

\footnotetext{
${ }^{\dagger}$ Department of Corporate Finance and Corporate Governance, Financial University under the Government of the Russian Federation, 125993, 49 Leningradskiy Ave., Moscow, Russian Federation

${ }^{*}$ Corresponding Author, Email: Nk2@list.ru

* Department of Economics, Mineral and Raw Materials Sector, Russian State Geological Prospecting University, 117485, 23 Miklouho-Maclay lane, Moscow, Moscow, Russian Federation

'̇ Department of Finance and Credit, Chechen State University, 366007, Boulevard Dudayev, Grozny, Russian Federation

Î Department of General Theoretical Disciplines, Moscow Automobile and Road Construction State Technical University (MADI), 125319, 64 Leningradskiy Ave., Moscow, Russian Federation

'Department of World Economics, Universidad de Buenos Aires, Av. Córdoba 2122, 1113 Caba Ciudad de Buenos Aires, Argentina
} 


\section{Introduction}

The effectiveness and the need for cooperation in the field of public-private partnership (PPP) are being determined in the works of Turovskiy (2017) and Buckley et al., (2017). Property relations reforming in Russia requires not only scientific and theoretical rationale of the mechanism of introduction of new forms of management but also forecasting future changes (Silagadze, 2017; Silagadze, 2018).

Currently, the creation of modern and efficient infrastructure is one of the priority components of the country's development (Kryukova et al., 2016). Without this factor, it is impossible to ensure a decent quality of life for citizens (Titova \& Kireeva, 2017; Golubova, 2017). Due to the slow development of business, even in the ideal climate, transaction and logistics costs of business with the existing infrastructure are incredibly high. At the same time, one has to remember that the modernisation of infrastructure is the engine of economic development (Juknevičiene \& Bersenaite, 2016; Voreviciene \& Butkeviciene, 2017; Belitskaya, 2018).

The state programme for the economy revitalisation focuses on long-standing problems in the private sector, namely, unattractive conditions for running a business as well as in the public sector ineffective management of state property has led to a high degree of depreciation of fixed assets.

In this situation, the use of a PPP is the most effective way to solve these problems (Vanteeva $\&$ Hickson, 2016). This form of partnership has been effectively implemented in developed countries, the use of which, taking into account the specifics of the market, can contribute to the development of advanced infrastructure and the revival of investment activity of the private sector (Gugkayeva \&Tuayeva, 2017; Sivash et al., 2017). It provides an opportunity to consolidate the society on the basis of the strategic interests of the territories ensuring cooperation between the government, business and the population in solving socially important tasks, creates the atmosphere of trust, respect and mutual understanding, which remains extremely paramount for the country (Lukyanenko and Isik, 2017; Kolesnikov et al., 2018;). The key aim of this research is to accomplish the following objectives:

- to identify the category of risks in PPP;

- to identify the information base for solving the problem of optimising the indicator of the GDP investment intensity by revealing the share of the state and private sector in financing the investment projects;

- to identify the dynamic changes in the investment intensity of the GDP and the share of public and private sector participation in financing the investment projects for the EU;

- to identify the particularities of tender documentation;

- to identify the ways to manage risk;

- to analyse the sources of investment financing;

- to identify the most accepted principles of coordination of interests of the state and private business after agreements on public-private partnership.

The research begins with a discussion of the forms of risks entailed in PPP. Following this, it discusses the methodological approach to the coordination of the economic interests of the PPP participants.

\section{Risks in Public-Private Partnerships}

At the present stage of development of the EU economic system, PPP seems an effective way to develop its infrastructure (Schomaker, 2017; Bures, 2017). Even though commercial relations between the state and business have been arising for a long time, the widespread use of PPP in the developed countries has received only in recent decades. This was greatly facilitated by the fact that the implementation of the PPP projects ensures the active development of infrastructure and effective control of this process by the state (Shashkova, 2018a; Shashkova, 2018b). Business, in its turn, receives guarantees of profitable activity and takes 
responsibility for the results (Averkieva, 2017; Onkorova, 2017). It is also stated that private financing of public infrastructure contributes to the transfer of risks from the public sector to private companies. Under these circumstances, the analysis of the nature of risks in PPP projects, methods of their determination and effective mechanisms of their management acquire important theoretical and practical significance (Usenko et al., 2018).

There is a wide range of PPP forms which differ in objectives, the scope of services, legal structure and degree of solidarity in carrying the risk (Pinigin, 2017; Abikenov et al., 2019). The problem of risk, which was one of the reasons for the appearance of PPP, remains very acute and requires careful study for every project individually. During the project, implementation risks are divided into those who cannot be avoided, and those which can be fought with.

The first group includes ideological differences between private and public authorities, lack the flexibility of some projects and the specific risks of individual projects (Shore \& Tosun, 2017). Those which can be avoided include the insufficient level of competition during the tender process, insufficient distribution of risk and responsibility between the parties, constancy of income and economic obstacles. If the risk is identified in advance, it can be transferred in time to the party that can develop a plan to fight with it effectively (Shumarina, 2017).

The most significant risks for the state are:

- a technical mistake in the development stage of the project;

- choice of the irrational form of publicprivate partnership;

- bad faith on the part of a private partner;

- poor quality of services provided to consumers by a private partner (concessionaire).

The set of risks for a private partner can be divided into the following groups:

- risks which arise from the activities of public authorities;
- risks associated with the participation of the state as a partner in public-private partnership projects;

- business risks of public-private partnership projects;

- risks associated with protests of the population, public and international organisations.

Among the typical risks of implementation of infrastructure projects by PPP mechanisms, there are force majeure, political risks, and profitability risks, operational, construction, financial risks as well as the risk of default. Risk management of the PPP project is carried out at the stage of conclusion of the PPP project agreement between the public and private partners. This reduces risk management in a very short period before the start of the project (Alonazi, 2017). Besides, the capacity of risk management mechanisms depends to a large extent on the provisions of the tender documents approved for the tender to identify a private partner (Langhagen-Rohrbach, 2007).

The legislation does not ensure a simple way to change the conditions of PPP. In particular, it is uncertain what changes can require a repeat competition to determine the private partner. In this regard, effective risk management mechanisms should be provided at the stage of the competition to determine the private partner and finally fixed in the contract for the implementation of the PPP project (Koshkin, 2018).

The necessary conditions are those on which the parties should agree in order for the contract to be concluded. Risk management can be implemented within the framework of essential conditions of risk allocation. However, the provisions of the legislation provide the distribution of only the risks which are identified by the results of the analysis of the PPP project effectiveness (Hanson et al., 2016).

The legislation does not explicitly determine how the risks identified during the pre-contractual negotiations (or even at the later stage) can be distributed, but not taken into account in the performance analysis. For example, proposals 
under the terms of the partnership agreement as a part of the bidder's proposal can contain proposals on risk management mechanisms. The possible ways of risk management, taking into account their specificity for a particular project, are not determined and can not be fully determined. To achieve this, it is advisable to provide a period of familiarisation with the draft tender documentation and amendments to it based on the results of comments received from potential bidders. It is also advisable to provide the cases in which it is possible to revise certain conditions of the contract without competition (Burov, 2019).

The legislation does not limit the possibility to ensure special conditions of the PPP project agreement or conclude additional (auxiliary) contractual instruments (for example, an investment agreement) (Gribust, 2018). At the time of presentation of conditions not envisaged by legislation, it is necessary to consider the extent of competence of the public partner. Also, to ensure the principle of equality of conditions, the state partner should provide such additional conditions in the tender documentation (Ouenniche et al., 2016).

The category of risks plays a significant role in public-private partnership (Postnikova, 2017). Like any economic activity, the PPP in the process of its implementation can be subject to certain impacts that can adversely affect the final results of the project. The critical factors in evaluating risks are the likelihood of their occurrence and the degree of consequences (impact) of the risks if any. In our opinion, it is necessary to form a distinctive approach to evaluating the risks of projects of public-private partnership, in particular, from the state.

Public sector funds to reduce risks include:

- implementation of research for the announcement of tenders;

- analysis of the best practices in the implementation and evaluation of the tender;

- reduction of opportunities for the unintentional assumption of risk;
- development of an action plan in case of the unforeseen interruption of the rendering of services for the project;

- structuring payments in the way that to minimise financial losses even in case of the inadequate level of project implementation;

- project insurance as required;

- analysis of the best practices in monitoring, control and management;

- recognition of the fact that the ratio of price and quality does not necessarily mean "low cost".

An essential role in studying the risks is played by an expert approach that allows involving a wide range of people who are competent in different issues regarding the components of the PPP project. The methodological issues are discussed in the following sections.

\section{Methodological Approach to the Coordination of Economic Interests of the PPP Participants}

We propose to substantiate the financial relations between the PPP participants and other aspects of transactions in the coordination of the interests of the state and private business by calculating such values of the parameters of PPP projects, for which the state will ensure the maximisation of revenues to the budget, and from the standpoint of partners, the optimisation of the values of the classical indicators for evaluating the effectiveness of investment projects (Baboshkina, 2018).

The base of the computational experiment is the following sequence of stages: model, algorithm and programme.

At the first stage, the construction of the socalled "equivalent" of the object (process) is carried out, reflecting its main characteristics employing mathematical formalisation. At the second stage, the algorithm is created for consistent implementation of the developed model. Besides, the model under study should be presented in the form suitable for the use of numerical methods. Also, in order to find the most accurate values of the required values, the identification of the sequence of calculation and 
logical operations are carried out. At the last third stage, there is created the software which can implement the algorithm of the developed model.

Thus, in the process of formulation, analysis and solution of extreme problems, there are the following directions:

- the formalisation of the problem under study;

- identification of the conditions for the existence of a solution to the formalised problem;

- determination of necessary and sufficient conditions of extremum;

- development of accurate and approximate methods for solving various classes of extreme problems.

Turning to the adaptation of the considered methods of optimisation of the conditions of the problem, it is fair to note that the base of the research will be reduced to the use of methods of unconditional multidimensional optimisation (in this case), the optimisation of the function of many variables. It is found that in the framework of the specifics of this study, it is most advisable to use direct search methods.

Considering our method within the framework of the tasks, it should be noted that the application of this approach to the problem of maximising the GDP investment intensity (multiplicative participation of the PPP) makes it possible not only to determine the share of the state and the private sector in financing the investment projects, but also analyse the dynamics of public and private sector investments (percentage of the GDP) as management parameters.

Taking into account the specifics of the task of optimising the proportions of the distribution of the structure of investments between public and private sources of financing, we propose the following algorithm for optimising the GDP investment intensity and its structure by sources of investment financing:
- formation of mathematical tools for achieving the goal, namely, the use of one of the methods of unconditional multidimensional optimisation is the method of configurations which simplifies the process of finding the extremum of the objective function as a function of many variables;

- the formalisation of the target function in the form of dependence of the GDP investment intensity on the share of the state and the private sector in the total investment;

- determination of the basic conditions for the implementation of the method of configurations in the optimisation of the objective function (acceptable level of accuracy of the result and transition step between iterations);

- carrying out a step-by-step iterative procedure for the implementation of the method of configurations and finding the iteration which corresponds to the maximum value of the GDP investment intensity at the given levels of the share of the public and private sectors of the economy.

The information base for solving the problem of optimising the indicator of the GDP investment intensity by determining the share of the state and the private sector in financing the investment projects are the time series presented in Table 1.

A detailed analysis of the information base of modelling the state's share in financing the projects in terms of investment interaction with business showed that the highest criterion of adequacy (the criterion of determination at the level of $92 \%$ ) had a polynomial of the third degree based on the data of Table 2 using the possibilities of statistical analysis. 


\begin{tabular}{|c|c|c|c|c|c|c|c|c|c|}
\hline Indicator & 2008 & 2009 & 2010 & 2011 & 2012 & 2013 & 2014 & 2015 & 2016 \\
\hline $\begin{array}{l}\text { GDP investment intensity } \\
\text { (capital investment to GDP), \% }\end{array}$ & 20.6 & 22.7 & 25.9 & 25.2 & 27.4 & 30.9 & 28.6 & 21.1 & 24.8 \\
\hline $\begin{array}{l}\text { Public sector investment, \% of } \\
\text { GDP }\end{array}$ & 2.4 & - & 4.3 & 2.7 & 2.9 & 3.1 & 4.1 & 2.6 & 3.4 \\
\hline
\end{tabular}

\begin{tabular}{|c|c|c|c|c|c|c|c|}
\hline Time & y & $x_{1}$ & $\mathbf{X}_{2}$ & $x_{1}{ }^{2}$ & $x_{2}{ }^{2}$ & $x_{1}{ }^{3}$ & $x_{2}{ }^{3}$ \\
\hline 2008 & 20.6 & 17.8 & 2.4 & 316.8 & 5.8 & 5639.8 & 13.8 \\
\hline 2009 & 22.7 & 19.0 & 3.1 & 361.0 & 9.6 & 6859.0 & 29.8 \\
\hline 2010 & 25.9 & 16.9 & 4.3 & 285.6 & 18.5 & 4826.8 & 79.5 \\
\hline 2011 & 25.2 & 20.0 & 2.7 & 400.0 & 7.3 & 8000.0 & 19.7 \\
\hline 2012 & 27.4 & 21.9 & 2.9 & 479.6 & 8.4 & 10503.5 & 24.4 \\
\hline 2013 & 30.9 & 23.8 & 3.1 & 566.4 & 9.6 & 13481.3 & 29.8 \\
\hline 2014 & 28.6 & 20.2 & 4.1 & 408.0 & 16.8 & 8242.4 & 68.9 \\
\hline 2015 & 21.1 & 17.2 & 2.6 & 295.8 & 6.8 & 5088.4 & 17.6 \\
\hline 2016 & 24.8 & 18.9 & 3.4 & 357.2 & 11.6 & 6751.3 & 39.3 \\
\hline Average values & 25.2 & 19.5 & 3.2 & - & - & - & - \\
\hline
\end{tabular}

where $y$ is the GDP investment intensity (II), \%; $\mathrm{x}_{1}$ is private sector investment $(\mathrm{PI}), \%$ from the GDP; $x_{2}$ is public sector investment (SI), \% of the GDP.

$$
I I=128,92 \quad 20,36 P I+17,31 S I+1,03 P I^{2} \quad 5,64 S I^{2} \quad 0,02 P I^{3}+0,68 S I^{3}
$$
application of column 1 of Table 2:

where $I I$ is GDP the investment intensity, \%; $P I$ is private sector investment, \% of the GDP; $S I$ is public sector investment, $\%$ of the GDP.

Besides, the results of the statistical analysis of the relations of investment intensity and the share of the state and the private sector in financing the investment projects are shown in Table 3, make it possible to make reasonable conclusions about the statistical significance of
We use a multi-factor nonlinear equation of the dependence of the GDP investment intensity on such management variables as private, and public sector investment can be based on the

the parameters of the equation, their standard mistakes and the interval limits of the levels of the selected factor features. 


\begin{tabular}{|c|c|c|c|c|}
\hline \multicolumn{5}{|l|}{ Table 3: Statistical Analysis of the Relations Between the Boundaries of the State and Private } \\
Sector Participation in Financing the Investment Projects \\
\hline Value of statistical model & Coefficient & Standard error & Lower 95 \% & Top 95 \% \\
\hline$y$ & 128.92 & 742.78 & -3067.03 & 3324.86 \\
\hline$x_{1}$ & -20.36 & 96.49 & -435.53 & 394.81 \\
\hline$x_{2}$ & 17.31 & 125.80 & -523.94 & 558.57 \\
\hline$x_{1}{ }^{2}$ & 1.03 & 4.75 & -19.40 & 21.46 \\
\hline$x_{2}{ }^{2}$ & -5.64 & 39.62 & -176.13 & 164.85 \\
\hline$x_{1}{ }^{3}$ & -0.02 & 0.08 & -0.35 & 0.32 \\
\hline$x_{2}{ }^{3}$ & 0.68 & 4.07 & -16.85 & 18.21 \\
\hline Sources & & & & \\
\hline
\end{tabular}

where $y$ is the GDP investment intensity (II), \%; $\mathrm{x}_{1}$ is private sector investment (PI), \% of the GDP; $\mathrm{x}_{2}$ is public sector investment (SI), \% of the GDP (Akhmetshin, 2018).

It should be noted that the presentation of algorithms for the calculation of individual indicators will be carried out using the following symbols: $y$ is investment intensity of GDP (II), \%; $\mathrm{x}_{1}$ is private sector investment $(\mathrm{PI}), \%$ of the GDP; $\mathrm{x}_{2}$ is public sector investment (SI), \% of the GDP. We set the coordinate directions of optimisation of objective function in the form of $s_{1}, s_{2}, \ldots, s_{n}$. Then we select the appropriate level $\varepsilon>0$ of the permissible value of the result accuracy to stop the implementation of the algorithm. Also, we set the initial step of the algorithm $\lambda>0$ to move from one iteration to the next and adjust the values of the control variables as well as the value of the accelerating factor $\alpha>0$ to find the optimal value in the right direction. After determining the above assumptions of the model for determining the limits of state participation in the financing of projects in the conditions of investment interaction with the business, we choose the starting point $X_{1}=\left(x_{1}^{1}, x_{2}^{1}, \ldots, x_{n}^{1}\right)$ numerical values of the factorial signs of functional dependence (1) and proceed to the main stage assuming:

$$
Y_{1}=X_{1} ; k=j=1
$$

Step 1. If the condition is satisfied, the mathematical formalisation of which has the form:

$$
f\left(Y_{j}+\lambda s_{j}\right)<f\left(Y_{j}\right)
$$

Then this step can be recognised as successful. In this case, one should move to the next second step after making the following assumption.

If the condition ( 3 ) is satisfied, then this relation takes the form of inequality:

$$
f\left(Y_{j}+\lambda s_{j}\right) \geq f\left(Y_{j}\right)
$$

This current step can be recognised as unsuccessful. In this case, one should verify again that the following condition is true:

$$
f\left(Y_{j}-\lambda s_{j}\right)<f\left(Y_{j}\right)
$$

If the ratio (5) is correct, one should proceed to the next step 2 by entering a guess of the form:

$$
Y_{j+1}=Y_{j}-\lambda s_{j}
$$

Otherwise, that is, when the condition is met:

$$
f\left(Y_{j}-\lambda s_{j}\right) \geq f\left(Y_{j}\right)
$$


Otherwise, when the condition is met:

$$
Y_{j+1}=Y_{j}
$$

Step 2. If $\mathrm{j}<\mathrm{n}$, it is necessary to return to the first step by typing the replacement of $\mathrm{J}$ by $\mathrm{j}+1$. In case of failure to comply with the above conditions, we move on to the next third step provided that the inequality is fair:

$$
f\left(Y_{n+1}\right)<f\left(X_{i}\right)
$$

Or go to the fourth step otherwise, that is, if the condition is met:

$$
f\left(Y_{n+1}\right) \geq f\left(X_{i}\right)
$$

Step 3. We introduce assumptions:

$$
\begin{gathered}
X_{k+1}=Y_{n+1} \\
Y_{1}=X_{k+1}+\alpha\left(X_{k+1}-X_{k}\right)
\end{gathered}
$$

We go to the first step by typing $\mathrm{j}=1$ and replacing $\mathrm{k}$ with $\mathrm{k}+1$.

Step 4. If the condition is true $\lambda \leq \varepsilon$, that this, fact indicates the completion of the calculations, that is $X_{K}$ acts as a solution to the optimisation problem. Otherwise, if this condition is not met, a replacement should be made $\lambda$ on $\frac{\lambda}{2}$ as well as the following assumption should be entered:

$$
Y_{j}=X_{k}, X_{k+1}=X_{k}
$$

After the implementation of these actions, one should return to the first step, after taking $\mathrm{j}=1$ and replacing $k$ value by $k+1$ value.

So, on the basis of the theoretically reduced sequence of implementation of the algorithm of the proposed method, we proceed to its study using real data (Abramov, 2015). Thus, the practical implementation of the steps of the iterative procedure proposed will be presented in the form of Table 2. Let us consider sequentially how the basic assumptions of the configuration method and the formation of each step of the calculations are introduced, that is, we describe in detail the essence and calculations of each graph given in Table 4 .
By specifying the coordinate directions of the objective function optimisation, we introduce the following assumptions:

- choose $\varepsilon=0.001>00$ as an acceptable level of accuracy of the result to stop the implementation of the algorithm;

- set the initial step of the algorithm $\lambda=$ $0.2>0$ to move from one iteration to the next and adjust the values of management variables (the share of the state and the private sector in the financing of investment projects);

- determine the magnitude of the accelerating multiplier $\alpha=0.5>0$ to find the maximum value of the GDP investment. 


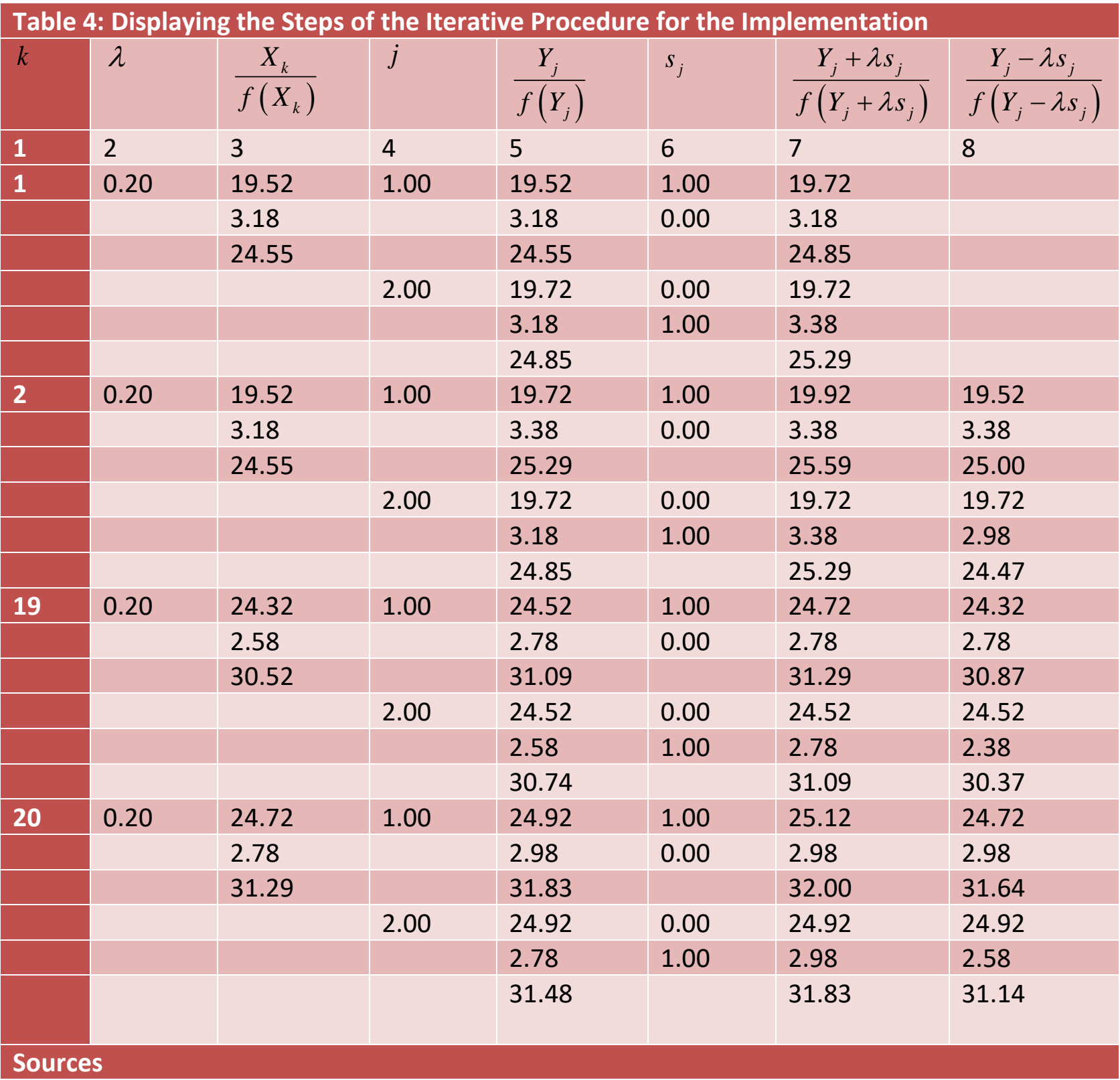

After determining the above assumptions of the model for determining the share of the state in financing the projects in terms of investment cooperation with the business, we choose the starting point $X_{1}=(20,72 ; 3,36)$ numerical values (arithmetic mean values) of the factorial signs of functional dependence and proceed to the main stage assuming that $Y_{1}=X_{1}, k=j=1$. Besides, we note that the classical formulation of the optimisation problem when solving it by the proposed method provides for the need to minimise the indicator chosen as a compelling feature. Therefore, when solving the problem of maximising the GDP investment intensity by achieving the relevant values of the shares of the public and the private sector in financing the investment projects, it is necessary to change the signs of inequalities used in the algorithm for the implementation of the methodology to the opposite ones.

Step 1. Iteration $1(\mathrm{k}=1)$. Since the condition is satisfied, the mathematical formalisation which has the form $f\left(Y_{j}+\lambda s_{j}\right)<f\left(Y_{j}\right)$, then this step can be recognised as unsuccessful. In this case, it is necessary to make a gradual transition to the second step and assume that $Y_{j+1}=Y_{j}$.

Step 2. Iteration 2 . Since $\mathrm{j}<\mathrm{n}$, you need to go back to the first step by entering the replacement $\mathrm{j}$ by $\mathrm{j}+1$. In the case of non-compliance with the above conditions, we move on to the next third 
step, provided the equity of inequality $f\left(Y_{n+1}\right) \geq f\left(X_{k}\right)$.

Step 3. Iteration 2. We introduce an assumption. Then we go to the first step by typing $j=1$ and replacing $\mathrm{k}$ with $\mathrm{k}+1$.

Similarly, we carry out a number of intermediate calculations until we get the optimal value.

Step 4. Iteration 20. If the condition is true $\lambda \leq \varepsilon$ , this fact indicates the completion of the calculations, that is, the $\mathrm{HC}$ is the solution of the optimisation problem.

\section{Conclusion}

Central aim of the research was to assess risks regarding the implementation of PPP projects in the world practice. Thus, the proposed scientific and methodological approach can be used to determine the optimal proportions of the distribution of investment between the public and private sectors. Its main advantage is the possibility of maximising the share of investments in the EU GDP structure by achieving optimal participation of the public and the private sector in financing the investment processes.

This study shows the developed methodological approach that allows to take into account economic interests of the participants (to approve possible loses and re-structure credit obligations) while concluding agreements on public and private partnership.

After PPP agreements, it is necessary to use the principle of coordination of interests of the public and private business. The methodological approach of the coordination of economic interests of the PPP participants developed by us consists in the implementation of multivariate calculations of the internal cost of the PPP project by the method of discounted cash flows, revision of the terms of the agreement and the choice of such values of the parameters of the PPP agreement. The implementation of this approach will maximise the internal cost of the project from the perspective of both private and public partners.

\section{References}

Abikenov, A., Idrysheva, S.K., Zharbolova, A.Z., Apakhayev, N., Buribayev, Y.A., \& Khamzina, Z.A. (2019). The problems of effectiveness and implementation of the international legal norms of the states of the Eurasian Economic Union (EAEU). Bulletin of the Georgian National Academy of Sciences, 13(1), 175-181.

Abramov, R.A. (2015). Management functions of integrative formations of differentiated nature, Biosciences, Biotechnology Research Asia, 12(1), 991-997.

Akhmetshin, E., Morozov, I., Pavlyuk, A., Yumashev, A., Yumasheva, N., Gubarkov, S. (2018). Motivation of personnel in an innovative business climate. European Research Studies Journal, 21(1), 352-361.

Alonazi, W.B. (2017). Exploring Shared Risks Through Public-Private Partnerships in Public Health Programs: A Mixed Method. BMC PublicHealth. Retrieved on 20 March 2019 from, https://staticcontent.springer.com/pdf/art\%3A10.1186\%2Fs 12889-017-4489-z.pdf?token=1544624344099eb0deaea824029911bce6f4882628eb97b36372 ad7f709b4aaa53ad78d1f2134f44c247efae47f61 7ce5a0bcc130d282eb3f780add021f602a7cdcd9 $34 a 46703$.

Averkieva, E.S. (2017). Public-Private Partnership as an Institution to Stimulate Business Activity. Journal of Economic Regulation, 8(1), 117-130.

Baboshkina, A.A., Savina, N.P., Morozov, I.V. (2018). Management processes in the development of the socio-economic environment of the region. Journal of Advanced Research in Law and Economics, 9(2), pp. 376385.

Belitskaya, M. (2018). Ecologically adaptive receptions control the number of pests in the ecosystems of transformed at the forest reclamation, World Ecology Journal, 8(2), 1-10.

Buckley, N.J., Mestelman, S., Muller, R.A., Schott, S., \& Zhang, J. (2017). The Effects of Communication on the Partnership Solution to 
the Commons. Environmental and Resource Economics, 70(2), 363-380. doi:10.1007/s10640017-0124-9

Bures, O. (2017). Contributions of private businesses to the provision of security in the EU: Beyond public-private partnerships. Crime, Law and Social Change, 67(3), 289-312. doi:10.1007/s10611-016-9650-6.

Burov A.G., Agüero D. (2019). Implementation of the principles of innovative entrepreneurship in the field. Academy of Entrepreneurship Journal, 25(1S), 1-5.

Golubova, M.I. (2017). Public-Private Partnership as a Mechanism for the Formation of Regional Localities. Economy and Entrepreneurship, 2-1(79-1), 738-741.

Gribust, I. (2018). Regulation of the state of plantings in the anthropogenically transformed territories: the principle of dendrological diversity. World Ecology Journal, 8(2), 11-21.

Gugkayeva, K.V., \& Tuayeva, L.A. (2017). PublicPrivate Partnership: Standard Approaches and New Solutions. Economy and Entrepreneurship, 2-1(79-1), 364-366.

Hanson, T., Wiles, G.J., \& Gaydos, J.K. (2016). A Novel Public-Private Partnership Model for Improving the Listing of Endangered Species. Biodiversity and Conservation, 25(1), 193-198.

Juknevičiene, V., Bersenaite, J. (2016). Collaborative governance as a prerequisite for the university-industry partnership for innovations' development: Results of empirical research. Public Policy and Administration, 15(1), 41-55.

Kolesnikov, Yu. A., Pavlyuk, A. V., Radachinsky, Yu. N., \& Rodionova, N. D. (2018). Problems of implementation of public-private partnership in Russia. European Research Studies Journal, 21, pp. 187-197.

Koshkin, A.P, Abramov R.A., Rozhina E.Y., Novikov A.V. (2018). Role of social representations in student motivation for acquiring further education. Interchange, 49(3), 313-341.
Kryukova, E., Vinichenko, M., Makushkin, S., Melnichuk, A., Bondaletov, V., \& Potekhina, E. (2016). On sustainable economic development of the mono town of Baikalsk. International Journal of Economic Research, 13(6), 2409-2424.

Langhagen-Rohrbach, C. (2007). Verkehrs infrastruktur und Public-Private-Partnership. Raumforschung und Raumordnung, 65(6), 539545. doi:10.1007/bf03183906

Lukyanenko, V.V., \& Isik, L.V. (2017). PublicPrivate Partnership as an Instrument for Infrastructure Development. In New Science: Experience, Traditions, Innovations (pp. 132137). Orenburg: Agency for International Studies.

Onkorova, B.Yu. (2017). Public-Private Partnership as a Form of Interaction Between Public Authorities and Business. In Innovation and Technological Development of Science (pp. 158-161). Ufa: Aeterna.

Ouenniche, J., Boukouras, A., \& Rajabi, M. (2016). An Ordinal Game Theory Approach to the Analysis and Selection of Partners in PublicPrivate Partnership Projects. Journal of Optimization Theory and Applications, 169(1), 314-343. doi:10.1007/s10957-015-0844-3

Pinigin, S.A. (2017). The Problem of Determining the Definition and Content of the Concept of Public-Private Partnership. In The 100th Anniversary of the Soviet Scientific Heritage: Cultural Traditions and Modern Practice (pp. 234-239). Tyumen: Mezhdunarodnyy Institut.

Postnikova, A.A. (2017). Public-Private Partnership as a Mechanism for Attracting Investment. Economy and Business: Theory and Practice, 1, 87-91.

Schomaker, R.M. (2017). Public-Private Governance Regimes in the Global Sphere. Public Organization Review, 17(1), 121-138. doi:10.1007/s11115-015-0333-z

Shashkova, A.V. (2018a). Corruption Is a Problem of Political Theory and Practice. Montenegrin Journal of Economics, 14(3), 143-154.

Shashkova, A.V. (2018b). Corporations and the State: Emerging of the Problem of Corporate Liability. Opción, 34(Special Issue 14), 432-458. 
Shore, J., \& Tosun, J. (2017). Assessing youth labour market services: Young people's perceptions and evaluations of service delivery in Germany. Public Policy and Administration. Retrieved from https://journals.sagepub.com/doi/full/10.1177/ 0952076717722192

Shumarina, Yu.A. (2017). Public-Private Partnership in the Transformation of the Norms of the Institutional Environment of the Region. In Economics and Management: Current Issues of Theory and Practice (pp. 251-254). Krasnodar: Krasnodar Center for Scientific and Technical Information.

Silagadze, A. (2017). History of Georgian economic thought: Relation between the center and the region. Bulletin of the Georgian National Academy of Sciences, 11(4), 138-144.

Silagadze, A. (2018). Some aspects of economic ideas in Shota Rustaveli's "the knight in the panther skin". Bulletin of the Georgian National Academy of Sciences, 12(1), 161-167.

Sivash, O.S., Burkaltseva, D.D., \& Ushakov, D.S. (2017). Activization of investment process in the agrarian sector. International Journal of Ecology and Development, 32(4), 169-182.
Titova, O.V, \& Kireeva, V.A. (2017). PublicPrivate Partnership: Standard Forms and New Solutions. In Strategic Initiatives for the SocioEconomic Development of Economic Entities of the Region in the Face of External Constraints (pp. 321-324). Voronezh: Izdatelstvo Ritm.

Turovskiy, A.A. (2017). Public-Private Partnership as an Object of Public Policy. Novalnfo. Ru, 1(59), 505-514.

Usenko, L.N., Bogataya, I.N., Bukhov, N.V., Kuvaldina, T.B., \& Pavlyuk A.V. (2018). Formation of an integrated accounting and analytical management system for value analysis purposes. European Research Studies Journal, 21, 63-71.

Vanteeva, N., \& Hickson, C. (2016). The effect of state-private co-partnership system on Russian industry. Review of Industrial Organization, 48(3), 333-356.

Voreviciene, J., Butkeviciene, E. (2017). Partnership of non-governmental organizations and local government agencies in the implementation of family policy: A case of Kaunas City municipality. Public Policy and Administration, 16(1), 121-137. 